PoS $\quad \begin{aligned} & \text { PROCEEDINGS } \\ & \text { OF SCIENCE }\end{aligned}$

\title{
Preface to PSTP 2013 Proceedings
}

\section{Don Crabb}

University of Virginia

E-mail: dgc3q@virginia.edu

\section{Matt Poelker}

Jefferson Lab

E-mail: poelkerejlab.org

XVth International Workshop on Polarized Sources, Targets, and Polarimetry, September 9-13, 2013

Charlottesville, Virginia, USA 
The 15th International Workshop on Polarized Sources, Targets and Polarimetry (PSTP 2013) was held at Newcomb Hall at the University of Virginia, Charlottesville, Virginia, USA from September 9, 2013 September 13th, 2013. It was sponsored jointly by the University of Virginia, Jefferson Laboratory and the International Spin Physics Committee.

The Workshop continued a long tradition of bringing together experts in the technical fields necessary to carry out particle physics experiments involving spin at accelerators around the world. The four previous workshops in this series were held at St. Petersburg, Russia in 2011, Ferrara, Italy in 2009, Brookhaven, USA in 2007 and Tokyo, Japan, 2005, following the tradition of circulating the Workshop among sites on different continents.

Eighty one scientists were registered for the Workshop but unfortunately four from Russia and two from China could not attend because of the long waiting periods now necessary to obtain a visa. Some of the information they were to bring to the workshop was presented by colleagues. The topics covered at the workshop were:

- Polarized Solid and Gas Targets

- Polarized Ion and electron (positron) Sources

- Polarized Electron and Ion Beam Polarimetry

- Applications of Spin

- New Initiatives

Also included was a session honoring the achievements of Vadim Dudnikov in proton and ion source development and a talk in memory of Michel Borghini and Franz Lehar for their contributions to solid polarized target development.

The Organizing Committee thank all the speakers and attendees for making this a memorable Workshop. We appreciate the financial support of the University of Virginia and of Jefferson Laboratory and we express our gratitude to David Craig and the University of Virginia Conference Services for their excellent administrative support. 